\title{
Implementing a Project-Based Learning Module in Urban and Indigenous Areas to Promote Young Children's Scientific Practices
}

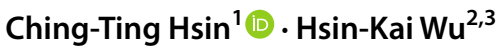

Accepted: 12 January 2022 / Published online: 24 January 2022

(c) The Author(s) 2022

\begin{abstract}
This study examined the impact of a project-based learning module on young children's scientific practices in urban and Indigenous areas. The module was developed by drawing upon early science standards and research on scientific practices and project-based teaching approaches. Ninety-eight children from northern Taiwan participated. Their average age was 5 years and 7 months, ranging from 4 years and 6 months to 6 years and 5 months. A performance assessment of scientific practices was administered before and after the module. Results of paired sample $t$ tests showed that children improved in overall practices and every sub-practice after taking the module. Both city and Indigenous children performed significantly better on the post-test, as did both the 4- and 5-year-old groups. ANCOVA results indicated no significant difference between urban and Indigenous children in the post-test scores of overall and most sub-practices; the only exception was that urban children had significantly better improvement on doing an experiment. Similar ANCOVA results were found for the 4- and 5-year-old groups; the 4-year-old group had significantly better improvement only on measuring. Results suggest that the module promoted scientific practices of children of different ages and ethnic backgrounds. This study sheds light on evidence-based early science curricula, early scientific practices, and the achievement of educational equity.
\end{abstract}

Keywords Project-based learning · Early science education · Indigenous children · Curriculum design

Children are born with curiosity about the world. Young children frequently ask questions related to scientific topics and are eager to learn how the world works. At home and school, they participate in mathematics activities, use technologies, and construct objects

Ching-Ting Hsin

cthsin@mx.nthu.edu.tw

1 Department of Early Childhood Education, National Tsing Hua University, 521, Nanda Rd., Hsinchu 30014, Taiwan

2 Graduate Institute of Science Education, National Taiwan Normal University, Taipei, Taiwan

3 Faculty of Education, University of Johannesburg, Johannesburg, South Africa 
representing the world they observe. Curricula that integrate STEM (Science, Technology, Engineering, Mathematics) disciplines are developmentally appropriate and can be implemented to enhance young children's scientific practices (Clements \& Sarama, 2016; French, 2004; Kähler et al., 2020; National Research Council, 2013). The development of quality early STEM curricula has received growing research attention in recent decades. Some examples from the USA include Samarapungavan et al.'s (2009) Science Literacy Project which fostered kindergarteners' scientific practices, and French's (2004) ScienceStart! Curriculum to improve preschoolers' language and scientific practices. Another example is Little Scientists implemented in Germany and Australia to engage young children in scientific inquiry (Haus der kleinen Forscher Foundation, 2017; MacDonald et al., 2020).

Among the early science curricula and studies, views on whether young children are capable of developing scientific practices vary. Researchers have argued that some scientific practices can only be enacted by older children. For example, Piekny and Maehler (2013) indicated that children cannot identify variables and do experiments until age 7. However, recent studies have found that young children can learn and improve scientific practices with guidance (e.g., Borgerding \& Raven, 2018; van der Graaf et al., 2015). These inconsistent arguments about children's development of science practices may stem from adopting different learning theories or from involving children of different ages. More empirical evidence is thus required to understand how scientific practices can be fostered and supported at a young age. Particularly, among the early science programs, only Peterson and French (2008) studied the scientific practices of 3- to 5-year-old preschoolers. Examining the scientific practices of children aged 5 and younger is needed. Furthermore, making comparisons and exploring differences between children of different ages could contribute to the understanding of children's development of scientific practices and the effect of a learning module on fostering the scientific practices of children with different initial performances.

In addition to implementing quality early science programs to enhance scientific practices, ensuring equal learning opportunities for young children of diverse cultural backgrounds is critical and would help decrease achievement gaps (Siraj \& Mayo, 2014). Research has shown that Indigenous students in Australia have lower achievement and participation in science than non-Indigenous students at every educational level (Cooper et al., 2020). Similar findings regarding Indigenous students' lower science literacy, engagement, and achievements have been observed in the USA, New Zealand, and Taiwan (Lin et al., 2017; Mead et al., 2010; Woods-McConney et al., 2013). Compared to the national average, a higher percentage of Indigenous children in Taiwan come from low-income families. Around half of Indigenous families are located in remote areas including those who participated in this study. While mainstream families in cities may afford afterschool science programs and camps, and have access to public science learning resources such as science museums and events, Indigenous families in rural areas rely more on schools to provide children with science learning opportunities. More quality early science curricula are needed for Indigenous children. We therefore compared the effects of a quality science module on the science practices of urban and Indigenous children who may have different initial performances due to unequal science learning opportunities. Doing so could inform the improvement of early science curricula to help decrease the science achievement gaps between the two groups.

We designed and implemented a project-based learning module in urban and Indigenous areas of Taiwan to promote young children's scientific practices. The project-based approach was adopted because past research on early science curricula revealed the importance of a structured approach and adult guidance. The researchers believed that in addition 
to free play, adults' intentional teaching and scaffolding enrich children's science learning (Hsin \& Wu, 2011; Peterson \& French, 2008). Such a structured approach involves adults' "deliberate sequencing of materials and activities, co-planning and pacing of activities, scaffolding children's enactment of activities, planful integration of a variety of ways to explore a particular topic" (French, 2004, p. 140). The project-based learning approach (Krajcik \& Czerniak, 2018) guides children to make in-depth, contextual investigations of topics. This approach engages students in asking scientific questions and conducting investigations (e.g., collecting information from different sources, doing experiments, making observations) to answer the questions. It also allows children to explore a science topic meaningfully, helps them learn scientific concepts, and promotes their scientific practices (Helm \& Katz, 2016; Krajcik \& Czerniak, 2018).

The purpose of this study was thus to examine the impact of a project-based learning module on urban and Indigenous kindergarteners' scientific practices by addressing the following research questions.

1. What are the effects of the project-based learning module on scientific practices of 4- and 5-year-old children in urban and Indigenous areas?

2. Do children in urban and Indigenous areas perform differently on scientific practices after engaging in the module?

3. Do the 4- and 5-year-old groups perform differently on scientific practices after engaging in the module?

\section{Young Children's Scientific Practices}

\section{Early Science Standards}

To define the learning objectives of scientific practices for young children in the projectbased learning module, science standards from the USA and Taiwan were adopted. In the USA, the Framework for K-12 Science Education (National Research Council, 2012) and Next Generation Science Standards (NGSS) (National Research Council, 2013) stressed students' learning of scientific and engineering practices, where "practice" involves the integration of scientific knowledge and inquiry skills. The development of scientific practices equips children to explore environments using scientific inquiry, to find answers to their questions, and to seek solutions for the challenges they face. According to NGSS, the eight practices appropriate for children to develop from kindergarten to second grade are Asking questions and defining problems; Developing and using models; Planning and carrying out investigation; Analyzing and interpreting data; Using mathematics and computational thinking; Constructing explanations and designing solutions; Engaging in argument from evidence; and Obtaining, evaluating, and communicating information.

The scientific practices for children aged 2 to 6 in Taiwan can be found in the Early Childhood Education and Care (ECEC) Curriculum Framework (Ministry of Education, 2017) that emphasizes the development of children's inquiry processes according to three aspects: (1) Collecting information about mathematics, natural phenomena, and artifacts; (2) Organizing information about mathematics, natural phenomena, and artifacts; and

(3) Solving problems or answering questions by working with others to explore possible answers or solutions, to discuss and find out answers or solutions, and to communicate about the results. 
In addition to the NGSS and ECEC frameworks that provided guidelines for determining the learning objectives of the curriculum module in this study, we also searched for empirical evidence and foundations of early scientific practices. We referred to previous studies to identify scientific practices that are developmentally appropriate for young children.

\section{Research on Scientific Practices for Young Children}

Previous studies on young children's scientific reasoning, process skills, and abilities have provided an empirical foundation for scientific practices for young children. These science skills constitute an essential part of scientific practices, as the practices intertwine process skills with science content. Additionally, instructional interventions have been developed to promote science skills and abilities. Thus, the scholarly work on process skills, experimental abilities, and related interventions is reviewed and discussed as follows.

\section{Science Process Skills}

Process skills include asking questions, doing investigations, interpreting and evaluating evidence, and formulating and communicating explanations (Jirout \& Zimmerman, 2015). Preschoolers' and kindergarteners' scientific process skills can be fostered by early science programs. For example, a Sense-Based Science Education Program in Turkey developed by Tekerci and Kandir (2017) reinforced 5-year-olds' observing, comparing, classifying, measuring, recording, communicating, inferring, and guessing skills. Experimental group children in the study improved their science process skills more than control group children.

The Great Explorations in Math and Science program created by Unal and Saglam (2018) enhanced Turkish kindergarteners' problem solving and science process skills, for example, asking questions, building hypotheses, collecting and analyzing information, and making inferences. The results revealed that the experimental group children outperformed those in the control group on problem solving but not on science process skills.

Samarapungavan and colleagues conducted a Science Literacy Project in the USA and created inquiry-based science units for kindergarteners (Mantzicopoulos et al., 2013; Samarapungavan et al., 2009). Children' process skills were assessed, including their abilities to ask science questions, make predictions, evaluate and interpret evidence, and use tools to gather, record, and share data. Their comparative studies showed that children engaging in inquiry-based science activities had better scores for science process skills than children doing regular science activities (e.g., Mantzicopoulos et al., 2013).

Another early science program in the USA is the Science Start! Curriculum designed to enhance preschoolers' language development and science process skills such as asking questions, planning, making predictions, observing, classifying, and representing information on processes and results (French, 2004). Although the curriculum covered a wide range of science process skills, only how children explained observed phenomena and causal connections was examined (Peterson \& French, 2008).

Although the aforementioned research on early science programs evaluated the development of young children's process skills, most studies involved fewer than 50 participants. More studies with larger samples are needed to gain a better understanding of the effects of early science programs. Also, participants in most studies were 5-year-olds and older. Only Peterson and French (2008) studied 3- to 5-year-old preschoolers. More research attention 
should be paid to preschoolers younger than 5. Lastly, some scientific practices were not assessed in the aforementioned studies (i.e., doing experiments) or it was not clearly explained how they were assessed (i.e., observing, comparing, classifying, measuring, communicating). According to the NGSS and ECEC framework, these are also critical scientific practices for young children. More studies are reviewed below to indicate whether and how young children can develop these practices.

\section{Doing Experiments}

Researchers have disputed preschoolers' and kindergarteners' capability of doing experiments. Experimentation involves identifying, controlling, and manipulating variables (Jirout \& Zimmerman, 2015; van der Graaf et al., 2015). Some researchers have argued that preschoolers do not understand the meaning of experimentation, believing that it is not until age 7 or 8 that children can control variables and make justifications (Bullock \& Ziegler, 1999; Piekny \& Maehler, 2013). However, recent studies on preschoolers' control of variables found that with the assistance of technology or adults, 4- and 5-year-olds could manipulate variables to complete a task. For example, van der Graaf et al. (2016) used a computer game to examine the kindergartners' control of variables strategy, and van der Graaf et al. (2015) found that with adults' verbal assistance in encoding the controlling and manipulating variables, 4- and 5-year-olds could design multivariable experiments. Dejonckheere et al. (2016) also found that teachers' guidance regarding paying attention to causal and non-causal variables was found to enhance preschoolers' ability to test one variable at a time.

\section{Making Systematic Observations}

Making systematic observations is another essential aspect of collecting data related to science questions (e.g., Gelman \& Brenneman, 2012; Monteira \& Jiménez-Aleixandre, 2016). Systematic observations require carefully using five senses to observe, describe, record, compare, and contrast the features of organisms, objects, or phenomena (Gelman \& Brenneman, 2004, 2012). Borgerding and Raven (2018) revealed that 5- to 6-year-old children could categorize living and non-living objects correctly, whereas younger children struggled with discerning fossils and recent rocks and bones. Kirkland et al. (2015) examined 3- to 5-year-olds' ability to make classifications, and assessed children according to two sorting tasks: free and dichotomy tasks. They found that after participating in intervention sorting activities, most of the experimental group 3- to 5-year-olds improved their sorting level. Together, these studies suggest that with guidance, young children are capable of making systematic observations, including observing and distinguishing features, and using features to classify or sort objects.

\section{Employing Tools and Measuring}

Doing science requires the use of appropriate tools to make measurements and collect data. In Samarapungavan et al.'s (2009) Science Learning Assessment for kindergarteners' understanding of science inquiry, some questions were related to the use of tools, for example, microscope, digital scale, and thermometer, to record and collect data. Their studies showed that after participating in the inquiry-based program, children improved their 
understanding of using tools for science investigations (e.g., Mantzicopoulos et al., 2013). However, young children may encounter some challenges when using tools for measuring. Solomon et al. (2015) identified kindergarteners' difficulty understanding that a ruler is a set of countable interval units, and revealed children's less developed inhibitory control and reliance on surface features, implying that instruction on using measuring tools with numbers is necessary.

\section{Scientific Practices for Children Aged 4 to 6}

We synthesized the scientific practices suggested by early learning science standards and the previous research on young children's scientific skills to form a framework of scientific practices for young children aged 4 to 6 (Table 1). This framework comprises six major practices (exploring, questioning, predicting, planning, investigating, and communicating) and 17 sub-practices. A project-based learning module was designed based on the framework to enhance children's scientific practices, and a performance assessment was developed.

Because it is not possible to examine all practices in an assessment and to cover all practices within a learning module, this study addressed six sub-practices identified in the aforementioned studies as being essential to early science education and frequently performed in the module: making a plan, making systematic observations, employing equipment and tools, measuring, doing an experiment, and sharing.

\section{Designing a Project-Based Learning Module}

\section{Project-Based Approach}

Science education and early childhood education researchers advocate the use of a projectbased approach to develop curricula that provide children with meaningful and rich contexts for scientific investigations (e.g., Helm \& Katz, 2016; Krajcik \& Czerniak, 2018). Krajcik and Czerniak (2018) stated five essential features of the project-based approach for science learning: (1) Establishing relevance to students' lives through exploring and asking questions for investigations; (2) Engaging students in the practices of science and engineering such as conducting investigations, analyzing data, and constructing models; (3) Collaborating with peers, teachers, and community members to find solutions; (4) Using technology tools to learn science; and (5) Creation of artifacts to show what students have learned.

Helm and Katz (2016) argued that the project approach for young investigators involves investigations and teachers' intensive guidance and scaffolds in three phases: (1) Exploring and identifying investigation questions: Possible topics are initiated by teachers or children. Teachers identify what children have learned and guide them to devise questions for an investigation; (2) Preparing for and conducting investigations: Teachers select possible field-sites and prepare children's data collection and representation skills. When children conduct investigations in the selected field-site, teachers introduce more resources, such as books, experts, and information. Children use the learned knowledge to construct a play environment where they create models and displays and role play about the investigated topic; (3) Concluding the project: Children prepare and conduct the culminating event to share with others what they have learned. Teachers review the project and assess children's learning. 


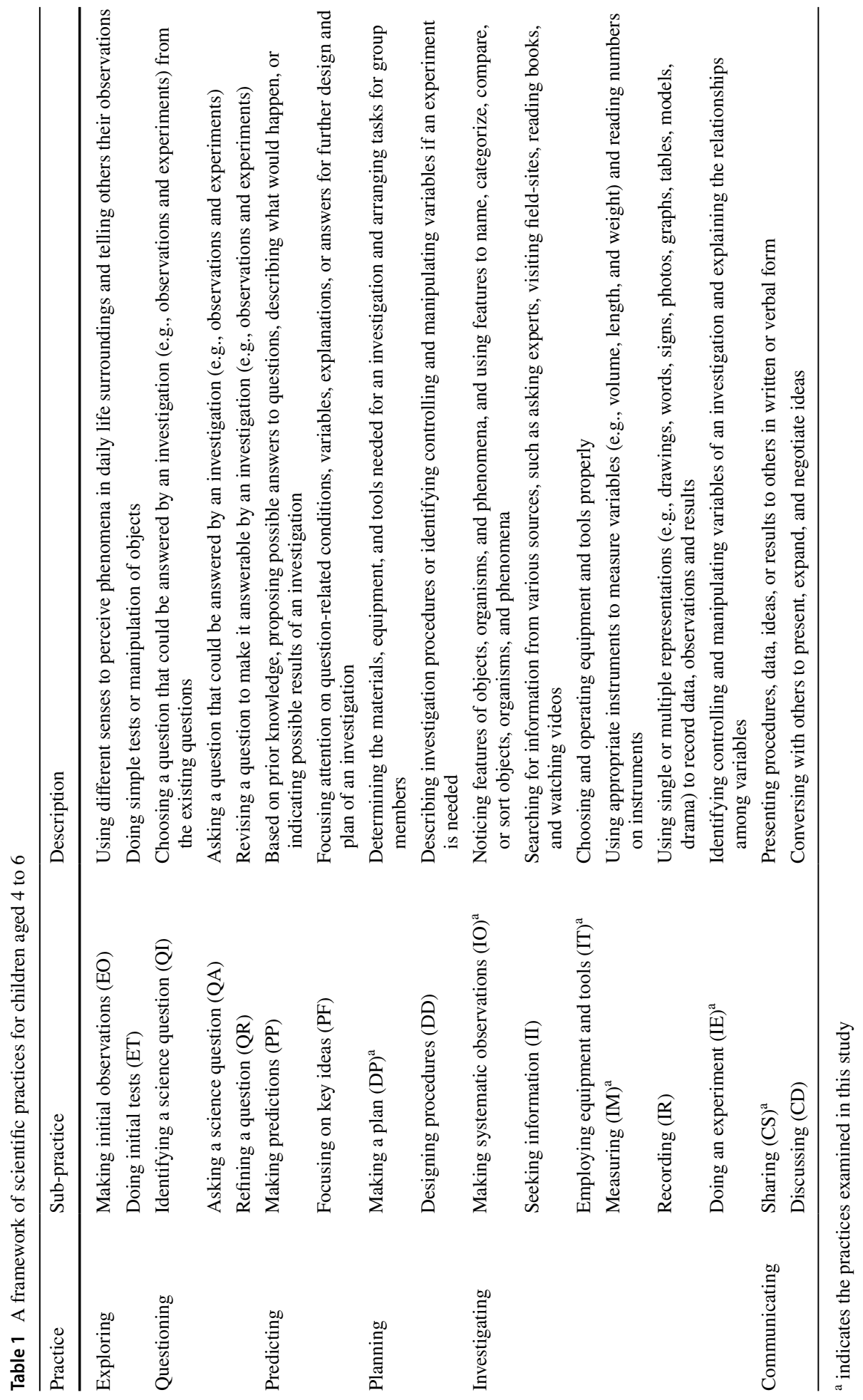


The project-based approaches from science education and early childhood education share similar features that became the principles for the instructional design in this study. First, the project is driven by questions that could contextualize the content and the topic to be explored and connect to children's lives and cultural experiences. Second, children are encouraged to plan and conduct investigations through a series of collaborative activities including experiments, systematic observations, field-sites visits, expert interviews, and parental involvement. Third, learning activities should engage students in scientific practices with the use of a variety of simple tools, daily digital equipment, and learning technologies. Fourth, children are encouraged to design and create artifacts to externalize their understandings. Finally, children are provided with opportunities to share and communicate their ideas in a play environment. These design features could contextualize science learning in children's daily and cultural experiences, stimulate children's interest in science, and engage them in meaningful scientific investigations (Krajcik \& Czerniak, 2018). This approach is therefore appropriate for children in both urban and Indigenous areas.

\section{Project-Based Learning Module: Spinning Tops}

Drawing upon the project-based design principles, we designed a curriculum module on spinning tops (Table 2). Five integration questions were proposed to contextualize the content to be explored. Children were encouraged to collaboratively design and conduct experiments with peers. Field-site visits and expert interviews allowed them to ask questions, share ideas, and learn from community members. They used a variety of tools for measurement and artifact creation when they enacted scientific practices such as doing experiments and making observations. They designed individual and group spinning tops to apply and show what they had learned. Creating spinning tops allowed them to perform scientific practices such as planning, communicating, and employing equipment and tools. Finally, competitions and games in the module provided a play environment for them to engage in scientific practices. In multiple activities, they shared and discussed their ideas with peers and teachers.

\section{Methods}

\section{Implementation of the Module}

After the project-based learning module was developed, two teacher workshops were held for kindergarten teachers from urban and Indigenous areas. During the workshops, we helped teachers understand how to implement the module, and collected their feedback to revise it. Teachers were asked to follow the lesson plans in order to ensure the instructional fidelity of the content. A lesson plan included the objectives, agenda, suggested questions for guiding children, and materials needed. However, to contextualize the science activities (Krajcik \& Czerniak, 2018), they could also improvise and expand the activities according to local contexts, children's prior knowledge, interests, and questions. For example, teachers from Indigenous villages were encouraged to use natural materials as spinning tops, such as a tree nut common to the area. They were also suggested to guide children to integrate Indigenous patterns into the spinning top design.

As shown in Table 2, the spinning tops module was composed of five investigation questions. The module comprised 17 lessons, each lasting an average of $40 \mathrm{~min}$. 


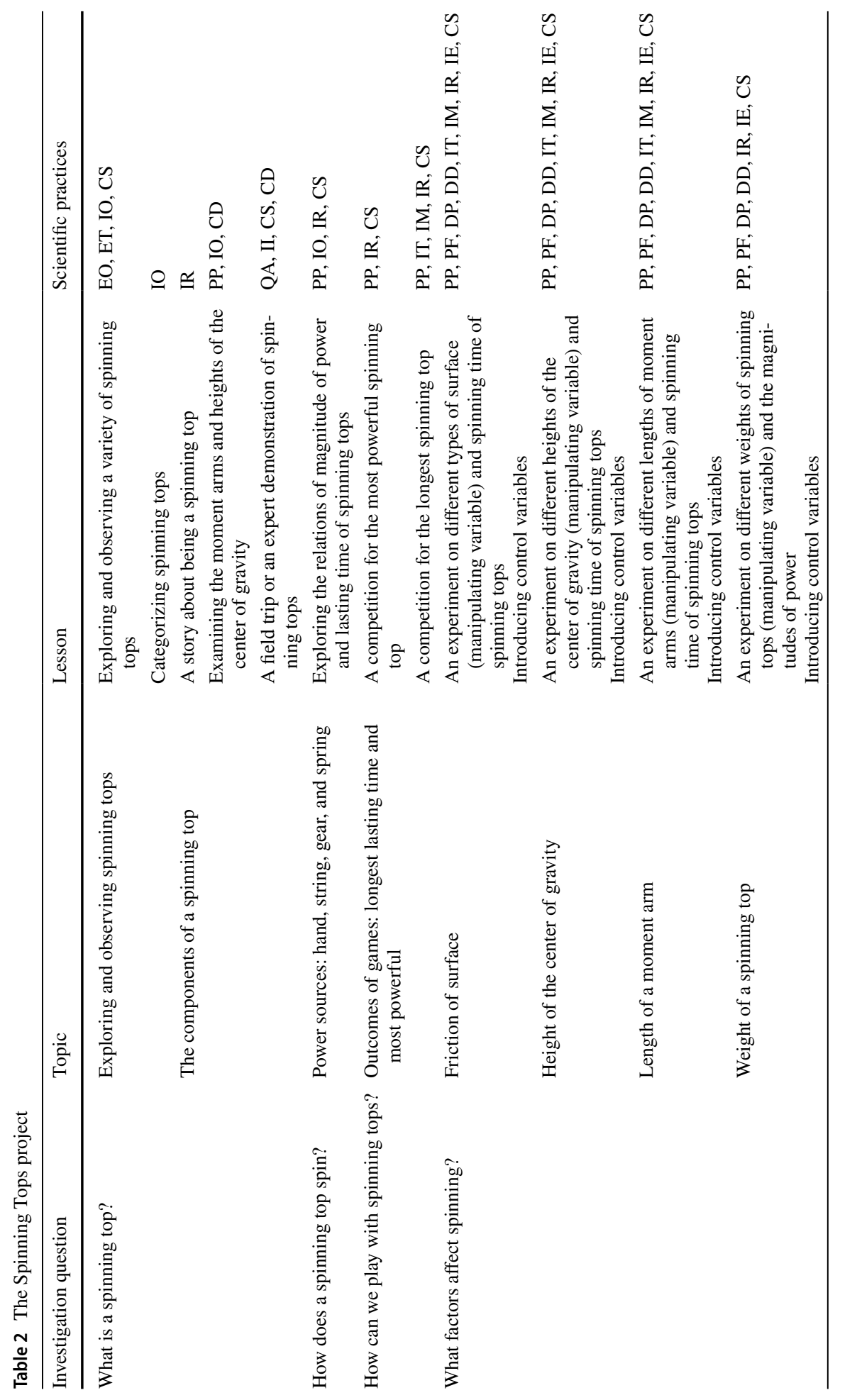




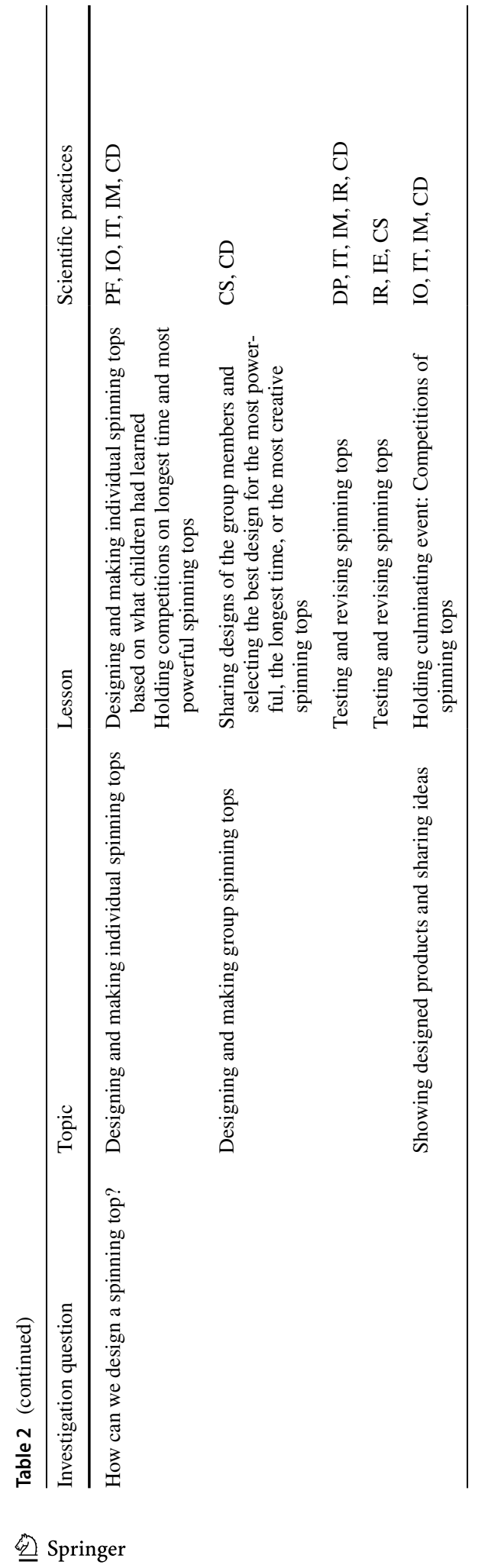


Teachers conducted two to three lessons each week, taking approximately 2 months to complete the module.

\section{Participants}

Purposive sampling was adopted. We recruited two classes with three teachers from two public kindergartens in two big cities where the second author worked, and four classes with four teachers from three public kindergartens in remote Indigenous villages where we had developed long-term, collaborative relationships with the kindergartens. We invited teachers who were willing to implement the module and had experience of guiding children to conduct projects and connecting their curricula to children's lives and cultural experiences. All seven teachers reported that they rarely conducted science projects. Among them, five teachers had a bachelor's degree and two teachers in the cities had a master's degree. Their average age and number of teaching years were 35.8 and 13.3. Five were certified teachers and two in Indigenous areas were certified caregivers. All kindergartens were located in northern Taiwan. We collected data from more classes in Indigenous areas because their class size was smaller.

A total of 98 children participated in the study, of whom 46 were boys and 52 were girls, while 53 lived in cities and 45 in Indigenous villages. In terms of age groups, 35 were in the 4-year-old group and 63 were in the 5-year-old group. In Taiwan, the "age" of the group was similar to the grade level and referred to the children's age when they were enrolled in the kindergarten. This study was conducted 6 months after their enrollment so children's ages ranged from 4 years and 6 months to 6 years and 5 months. The average ages of the 4- and 5-year-old groups were therefore 5 and 6 years old respectively and the average age of all children was 5 years and 7 months (Table 3). Among the six participating classes, five were mixed-age classes and one was a 5-year-old class.

In terms of ethnicity, 51 were mainstream Han Chinese, 40 were Indigenous (mostly Atayal Tribe), and seven were new-immigrant children (one parent from a foreign country). The percentages of low-income families in the two city classes were $1.7 \%$ and $3 \%$, and the average percentage for the classes in the Indigenous villages was $31 \%$. Table 3 gives their background information.

Table 3 Participants' background information

\begin{tabular}{|c|c|c|c|c|c|c|c|c|c|c|c|c|}
\hline \multirow[t]{2}{*}{ Groups } & \multirow[t]{2}{*}{$n$} & \multirow{2}{*}{$\begin{array}{l}\text { Average } \\
\text { age }\end{array}$} & \multicolumn{4}{|c|}{ Gender } & \multicolumn{6}{|c|}{ Ethnicity } \\
\hline & & & Boy & $\%$ & Girl & $\%$ & Main & $\%$ & Indigenous & $\%$ & $\begin{array}{l}\text { New } \\
\text { immi- } \\
\text { grant }\end{array}$ & $\%$ \\
\hline Urban & 53 & $5 ; 08$ & 27 & 50.9 & 26 & 49.1 & 47 & 88.7 & 1 & 1.9 & 5 & 9.4 \\
\hline Indigenous & 45 & $5 ; 06$ & 19 & 42.2 & 26 & 57.8 & 4 & 8.9 & 39 & 86.7 & 2 & 4.4 \\
\hline 4-year-old & 35 & $5 ; 00$ & 11 & 31.4 & 24 & 68.6 & 14 & 40.0 & 19 & 54.3 & 2 & 5.7 \\
\hline 5-year-old & 63 & $6 ; 00$ & 35 & 55.6 & 28 & 44.4 & 37 & 58.7 & 21 & 33.3 & 5 & 7.9 \\
\hline Total & 98 & $5 ; 07$ & 46 & 46.9 & 52 & 53.1 & 51 & 52.0 & 40 & 40.8 & 7 & 7.1 \\
\hline
\end{tabular}




\section{Performance Assessment of Scientific Practices}

The assessment examined six sub-practices: making a plan, making systematic observations, employing equipment and tools, measuring, doing an experiment, and sharing. Taskbased items were developed through a review of the research literature (e.g., Greenfield, 2015; Samarapungavan et al., 2009; van der Graaf et al., 2015). Three researchers in the fields of science education and early childhood education reviewed the items to ensure face validity. A pilot assessment was conducted in which eleven 4- to 6-year-olds were interviewed and asked to perform the assessment tasks, with items revised accordingly.

Assessment was administered before and after the module for each participating child. Three researchers interviewed the participants. The coding scheme (rating scale) was developed through a comprehensive review and categorization of participants' responses to one item into different levels of practice. Different scores $(0,1,2$, and 3$)$ were assigned for an item where a higher score indicated a higher level of a practice. Established on 40 cases, the intercoder reliability was 0.92 , suggesting adequate agreement. In terms of reliability, the internal consistency was good (Cronbach's $\alpha=0.84$ ).

The assessment comprised 37 items with a full score of 69 . To assess the practices of making a plan, making systematic observations, employing equipment and tools, measuring, doing an experiment, and sharing, 6, 11, 4, 6, 5, and 5 items were designed respectively. Sample items for making a plan (DP) and doing an experiment (IE) are shown in Fig. 1. For example, in the ramps task, children were asked to make a plan for an experiment: "If you are going to do an experiment to see on which surface the toy cars run faster, what will you choose to use for the experiment?" (Fig. 1). A child choosing sufficient and appropriate materials for the experiment, such as two identical toy cars (or one car) and two ramps with different surfaces, gained the highest score of 2 points. In the following item, children were invited to use their chosen materials to do an experiment. When doing the experiment, children who identified controlling and manipulating variables and did the experiment as they planned received the highest score of 3 points.

\section{Data Analysis}

To answer the first research question and examine whether children improved their scientific practices after taking the module, paired sample $t$ tests were used to compare the

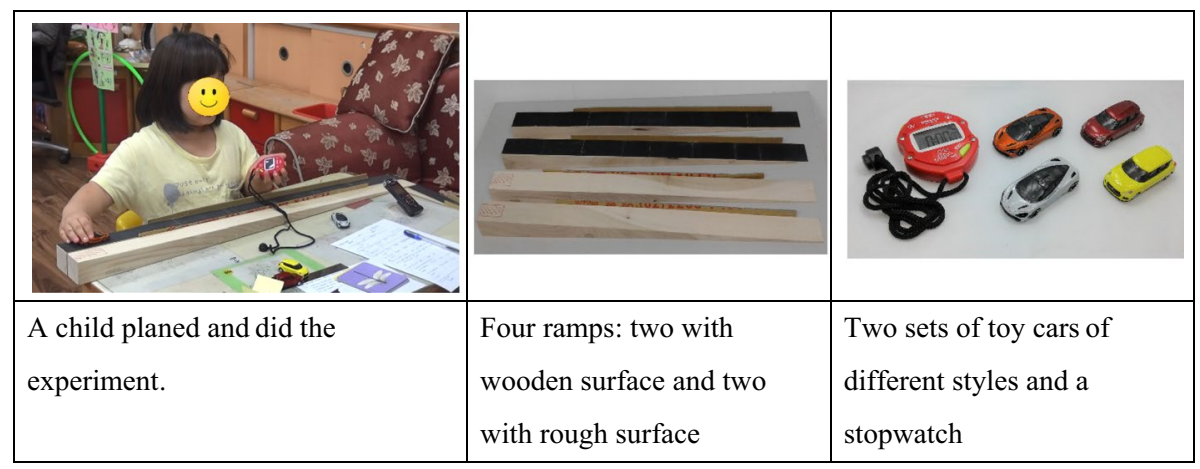

Fig. 1 Sample items from the performance assessment of scientific practices: the ramps task 
differences between pre-tests and post-tests for all participating children. Paired sample $t$ tests were also employed for in-depth understanding of how children improved in scientific practices regarding area and age. To answer the second and third research questions, how children from different areas and of different ages performed differently after participating in the module was examined. Analyses of covariance (ANCOVA) were applied to compare the differences in post-tests of children in urban and Indigenous areas as well as between 4- and 5-year-old groups. The pre-test scores were the covariate, and ANCOVA was performed to control for initial differences in the pre-test scores between groups.

\section{Results}

\section{Effects of the Project-Based Learning Module on Scientific Practices}

The first research question addressed the effects of the project-based learning module on children's scientific practices. As shown in Table 4, a significant difference was found between the pre-test and post-test for all participating children $(t(97)=13.48$, $p<0.001, E S=1.36)$. The result shows that they improved their overall scientific practices after engaging in the module. The effect size was large (Cohen, 1988). Furthermore, Table 4 reveals significant differences between pre-tests and post-tests for making a plan $(t(97)=6.67, p<0.001, E S=0.68)$, making systematic observations $(t(97)=9.78$, $p<0.001, E S=0.98)$, employing equipment and tools $(t(97)=7.08, p<0.001, E S=0.73)$, measuring $(t(97)=8.27, p<0.001, E S=0.83)$, doing an experiment $(t(97)=4.74$, $p<0.001, E S=0.48)$, and sharing $(t(97)=4.17, p<0.001, E S=0.43)$. That is, the children improved in every sub-practice after taking the module. The effect sizes of making systematic observations and measuring were large; for making a plan and employing equipment

Table 4 Paired sample $t$ test results for all participating children

\begin{tabular}{lllrlllll}
\hline Practice & Test & $N$ & \multicolumn{1}{l}{$M$} & $S D$ & $M_{\text {diff }} t$ & $p$ & $E S$ \\
\hline DP & pre & 98 & 4.07 & 1.52 & 1.43 & 6.76 & $<.001$ & 0.68 \\
& post & & 5.50 & 1.84 & & & & \\
IO & pre & 98 & 10.31 & 2.63 & 1.84 & 9.78 & $<.001$ & 0.98 \\
& post & & 12.14 & 2.41 & & & & \\
IT & pre & 98 & 2.24 & 0.73 & 0.57 & 7.08 & $<.001$ & 0.73 \\
& post & & 2.82 & 0.71 & & & & \\
IM & pre & 98 & 8.76 & 2.53 & 1.91 & 8.27 & $<.001$ & 0.83 \\
& post & & 10.66 & 2.23 & & & & \\
IE & pre & 98 & 2.20 & 1.54 & 1.02 & 4.74 & $<.001$ & 0.48 \\
& post & & 3.22 & 1.93 & & & & \\
CS & pre & 98 & 3.24 & 1.98 & 0.64 & 4.17 & $<.001$ & 0.43 \\
& post & & 3.89 & 1.93 & & & & \\
Total & pre & 98 & 30.83 & 7.02 & 7.41 & 13.48 & $<.001$ & 1.36 \\
& post & & 38.23 & 7.73 & & & & \\
\hline
\end{tabular}

DP, making a plan; IO, making systematic observations; IT, employing equipment and tools; IM, measuring; IE, doing an experiment; CS, sharing 
and tools they were medium; and for doing an experiment and sharing they were small (Cohen, 1988).

Table 5 shows the paired sample $t$ test results of children in the urban and Indigenous areas. In the urban area, children had significantly better scores in every sub-practice and overall practices after taking the module. The effect size of overall practices $(E S=1.46)$ was large. The effect sizes of making a plan, making systematic observations, and measuring were large; for employing equipment and tools and doing an experiment, they were medium; and for sharing, the effect size was small.

Children living in Indigenous areas also performed significantly better in the post-tests of every sub-practice and overall practices. The effect size of overall practices $(E S=1.25)$

Table 5 Paired sample $t$ test results for children in urban and indigenous areas

\begin{tabular}{|c|c|c|c|c|c|c|c|c|}
\hline Practice & Test & $n$ & $M$ & $S D$ & $M_{\text {diff }}$ & $t$ & $p$ & $E S$ \\
\hline \multicolumn{9}{|l|}{ Urban } \\
\hline DP & $\begin{array}{l}\text { pre } \\
\text { post }\end{array}$ & 53 & $\begin{array}{l}4.00 \\
5.74\end{array}$ & $\begin{array}{l}1.58 \\
1.89\end{array}$ & 1.74 & 6.79 & $<.001$ & 0.93 \\
\hline IO & $\begin{array}{l}\text { pre } \\
\text { post }\end{array}$ & 53 & $\begin{array}{l}11.09 \\
12.83\end{array}$ & $\begin{array}{l}2.40 \\
2.36\end{array}$ & 1.74 & 6.83 & $<.001$ & 0.94 \\
\hline IT & $\begin{array}{l}\text { pre } \\
\text { post }\end{array}$ & 53 & $\begin{array}{l}2.32 \\
2.92\end{array}$ & $\begin{array}{l}0.64 \\
0.68\end{array}$ & 0.60 & 5.72 & $<.001$ & 0.78 \\
\hline IM & $\begin{array}{l}\text { pre } \\
\text { post }\end{array}$ & 53 & $\begin{array}{r}9.49 \\
11.47\end{array}$ & $\begin{array}{l}2.38 \\
1.87\end{array}$ & 1.98 & 5.98 & $<.001$ & 0.82 \\
\hline IE & $\begin{array}{l}\text { pre } \\
\text { post }\end{array}$ & 53 & $\begin{array}{l}2.55 \\
3.85\end{array}$ & $\begin{array}{l}1.51 \\
1.97\end{array}$ & 1.30 & 4.03 & $<.001$ & 0.55 \\
\hline $\mathrm{CS}$ & $\begin{array}{l}\text { pre } \\
\text { post }\end{array}$ & 53 & $\begin{array}{l}3.62 \\
4.23\end{array}$ & $\begin{array}{l}2.07 \\
2.03\end{array}$ & 0.60 & 3.04 & .004 & 0.42 \\
\hline Total & $\begin{array}{l}\text { pre } \\
\text { post }\end{array}$ & 53 & $\begin{array}{l}33.08 \\
41.04\end{array}$ & $\begin{array}{l}6.37 \\
7.28\end{array}$ & 7.96 & 10.65 & $<.001$ & 1.46 \\
\hline \multicolumn{9}{|c|}{ Indigenous } \\
\hline DP & $\begin{array}{l}\text { pre } \\
\text { post }\end{array}$ & 45 & $\begin{array}{l}4.16 \\
5.22\end{array}$ & $\begin{array}{l}1.49 \\
1.76\end{array}$ & 1.07 & 3.11 & .003 & 0.46 \\
\hline IO & $\begin{array}{l}\text { pre } \\
\text { post }\end{array}$ & 45 & $\begin{array}{r}9.38 \\
11.33\end{array}$ & $\begin{array}{l}2.61 \\
2.24\end{array}$ & 1.96 & 6.97 & $<.001$ & 1.04 \\
\hline IT & $\begin{array}{l}\text { pre } \\
\text { post }\end{array}$ & 45 & $\begin{array}{l}2.16 \\
2.69\end{array}$ & $\begin{array}{l}0.82 \\
0.73\end{array}$ & 0.53 & 4.25 & $<.001$ & 0.63 \\
\hline IM & $\begin{array}{l}\text { pre } \\
\text { post }\end{array}$ & 45 & $\begin{array}{l}7.89 \\
9.71\end{array}$ & $\begin{array}{l}2.46 \\
2.27\end{array}$ & 1.82 & 5.70 & $<.001$ & 0.85 \\
\hline IE & $\begin{array}{l}\text { pre } \\
\text { post }\end{array}$ & 45 & $\begin{array}{l}1.80 \\
2.49\end{array}$ & $\begin{array}{l}1.49 \\
1.62\end{array}$ & 0.69 & 2.56 & .014 & 0.38 \\
\hline CS & $\begin{array}{l}\text { pre } \\
\text { post }\end{array}$ & 45 & $\begin{array}{l}2.80 \\
3.49\end{array}$ & $\begin{array}{l}1.79 \\
1.74\end{array}$ & 0.69 & 2.83 & .007 & 0.42 \\
\hline Total & $\begin{array}{l}\text { pre } \\
\text { post }\end{array}$ & 45 & $\begin{array}{l}28.18 \\
34.93\end{array}$ & $\begin{array}{l}6.90 \\
6.96\end{array}$ & 6.76 & 8.36 & $<.001$ & 1.25 \\
\hline
\end{tabular}

DP, making a plan; IO, making systematic observations; IT, employing equipment and tools; IM, measuring; IE, doing an experiment; CS, sharing 
was large. The effect sizes of making systematic observations and measuring were large; the effect size of employing equipment and tools was medium; and for making a plan, doing an experiment, and sharing they were small.

Table 6 reveals the significant differences in pre-tests and post-tests of every sub-practice and overall practices for the 4- and 5-year-old groups. Both age groups demonstrated significantly better practices in the post-test (overall practices: 4-year-old, $E S=1.59$; 5-year-old, $E S=1.26$ ). In the 4-year-old group, the effect sizes of the sub-practices ranged from 0.53 to 1.56 , while for the 5-year-old group, they were between 0.35 and 1.02 . The results suggested that the project-based module was effective for supporting the development of both age groups' scientific practices.

Table 6 Paired sample $t$ test results for the 4- and 5-year-old groups

\begin{tabular}{|c|c|c|c|c|c|c|c|c|}
\hline Practice & Test & $n$ & $M$ & $S D$ & $M_{\text {diff }}$ & $t$ & $p$ & $E S$ \\
\hline \multicolumn{9}{|c|}{ 4-year-old } \\
\hline DP & $\begin{array}{l}\text { pre } \\
\text { post }\end{array}$ & 35 & $\begin{array}{l}3.83 \\
5.11\end{array}$ & $\begin{array}{l}1.69 \\
1.91\end{array}$ & 1.29 & 3.16 & .003 & 0.53 \\
\hline IO & $\begin{array}{l}\text { pre } \\
\text { post }\end{array}$ & 35 & $\begin{array}{r}9.14 \\
10.97\end{array}$ & $\begin{array}{l}2.99 \\
2.82\end{array}$ & 1.83 & 5.43 & $<.001$ & 0.92 \\
\hline IT & $\begin{array}{l}\text { pre } \\
\text { post }\end{array}$ & 35 & $\begin{array}{l}2.14 \\
2.66\end{array}$ & $\begin{array}{l}0.81 \\
0.68\end{array}$ & 0.51 & 3.72 & .001 & 0.64 \\
\hline IM & $\begin{array}{l}\text { pre } \\
\text { post }\end{array}$ & 35 & $\begin{array}{r}7.00 \\
10.37\end{array}$ & $\begin{array}{l}2.35 \\
2.46\end{array}$ & 3.37 & 9.25 & $<.001$ & 1.56 \\
\hline IE & $\begin{array}{l}\text { pre } \\
\text { post }\end{array}$ & 35 & $\begin{array}{l}1.74 \\
2.60\end{array}$ & $\begin{array}{l}1.40 \\
1.52\end{array}$ & 0.86 & 3.26 & .003 & 0.55 \\
\hline $\mathrm{CS}$ & $\begin{array}{l}\text { pre } \\
\text { post }\end{array}$ & 35 & $\begin{array}{l}2.74 \\
3.60\end{array}$ & $\begin{array}{l}1.92 \\
1.87\end{array}$ & 0.86 & 3.30 & .002 & 0.56 \\
\hline Total & $\begin{array}{l}\text { pre } \\
\text { post }\end{array}$ & 35 & $\begin{array}{l}26.60 \\
35.31\end{array}$ & $\begin{array}{l}7.12 \\
8.35\end{array}$ & 8.71 & 9.39 & $<.001$ & 1.59 \\
\hline \multicolumn{9}{|c|}{ 5-year-old } \\
\hline DP & $\begin{array}{l}\text { pre } \\
\text { post }\end{array}$ & 63 & $\begin{array}{l}4.21 \\
5.71\end{array}$ & $\begin{array}{l}1.42 \\
1.78\end{array}$ & 1.51 & 6.27 & $<.001$ & 0.79 \\
\hline IO & $\begin{array}{l}\text { pre } \\
\text { post }\end{array}$ & 63 & $\begin{array}{l}10.95 \\
12.79\end{array}$ & $\begin{array}{l}2.17 \\
1.88\end{array}$ & 1.84 & 8.13 & $<.001$ & 1.02 \\
\hline IT & $\begin{array}{l}\text { pre } \\
\text { post }\end{array}$ & 63 & $\begin{array}{l}2.30 \\
2.90\end{array}$ & $\begin{array}{l}0.69 \\
0.71\end{array}$ & 0.60 & 6.03 & $<.001$ & 0.76 \\
\hline IM & $\begin{array}{l}\text { pre } \\
\text { post }\end{array}$ & 63 & $\begin{array}{r}9.73 \\
10.83\end{array}$ & $\begin{array}{l}2.07 \\
2.10\end{array}$ & 1.10 & 4.50 & $<.001$ & 0.57 \\
\hline IE & $\begin{array}{l}\text { pre } \\
\text { post }\end{array}$ & 63 & $\begin{array}{l}2.46 \\
3.57\end{array}$ & $\begin{array}{l}1.56 \\
2.05\end{array}$ & 1.11 & 3.68 & $<.001$ & 0.46 \\
\hline $\mathrm{CS}$ & $\begin{array}{l}\text { pre } \\
\text { post }\end{array}$ & 63 & $\begin{array}{l}3.52 \\
4.05\end{array}$ & $\begin{array}{l}1.97 \\
1.96\end{array}$ & 0.52 & 2.73 & .008 & 0.35 \\
\hline Total & $\begin{array}{l}\text { pre } \\
\text { post }\end{array}$ & 63 & $\begin{array}{l}33.17 \\
39.86\end{array}$ & $\begin{array}{l}5.81 \\
6.91\end{array}$ & 6.68 & 9.98 & $<.001$ & 1.26 \\
\hline
\end{tabular}

DP, making a plan; IO, making systematic observations; IT, employing equipment and tools; IM, measuring; IE, doing an experiment; CS, sharing 


\section{Comparison of Children in Urban and Indigenous Areas}

To answer the second research question, we employed ANCOVA to compare the differences in post-tests of each and overall scientific practices of children living in urban and Indigenous areas. The ANCOVA results showed no significant difference in most sub-practices and overall practices (Table 7); the only exception was that the urban group outperformed the Indigenous group in doing an experiment $\left(F=10.04, p<0.01, \eta^{2}=0.1\right)$ with a medium effect size (Richardson, 2011). In other words, children living in both areas had a similar level of development in most and overall scientific practices when their pre-test scores were controlled. However, children in Indigenous areas did not improve as much as the urban group in the practice of doing an experiment.

\section{Comparison of the 4- and 5-Year-Old Groups}

The 4- and 5-year-old groups differed in their pre-test scores of overall scientific practices $(t(96)=4.95, p<0.001)$. Thus, ANCOVA was used to compare the differences in posttests between the two groups. Table 8 shows no significant difference between the two age groups in the overall practices and in five of the six sub-practices. The two groups significantly differed only in measuring, where the 4-year-old group outperformed the 5-yearold group in this practice with a medium effect size (Richardson, 2011) after their pre-test scores were controlled and the post-test scores were adjusted $\left(F=6.88, p<0.01, \eta^{2}=0.07\right)$. The result indicated that the 4-year-old group improved more than the 5-year-old group did in measuring after taking the module, although their counterparts had a higher mean score in the post-test.

Table 7 ANCOVA results for comparisons of children in urban and indigenous areas

\begin{tabular}{|c|c|c|c|c|c|c|c|c|c|}
\hline \multirow[t]{2}{*}{ Practice } & \multirow[t]{2}{*}{ Group } & \multicolumn{2}{|c|}{ Pre-test } & \multicolumn{2}{|c|}{ Post-test } & \multicolumn{4}{|l|}{ ANCOVA } \\
\hline & & $M$ & $S D$ & $M$ & $S D$ & $M$ (adjusted) & $S E$ & $F$ & $\eta^{2}$ \\
\hline \multirow[t]{2}{*}{ DP } & Urban & 4.00 & 1.56 & 5.74 & 1.89 & 5.76 & 0.25 & 2.39 & .03 \\
\hline & Indigenous & 4.16 & 1.49 & 5.22 & 1.76 & 5.20 & 0.27 & & \\
\hline \multirow[t]{2}{*}{$\mathrm{IO}$} & Urban & 11.09 & 2.40 & 12.83 & 2.36 & 12.32 & 0.23 & 1.20 & .01 \\
\hline & Indigenous & 9.38 & 2.61 & 11.33 & 2.24 & 11.93 & 0.25 & & \\
\hline \multirow[t]{2}{*}{ IT } & Urban & 2.32 & 0.64 & 2.92 & 0.68 & 2.90 & 0.09 & 1.74 & .02 \\
\hline & Indigenous & 2.16 & 0.82 & 2.69 & 0.73 & 2.72 & 0.10 & & \\
\hline \multirow[t]{2}{*}{ IM } & Urban & 9.49 & 2.38 & 11.47 & 1.87 & 11.17 & 0.26 & 8.03 & .08 \\
\hline & Indigenous & 7.89 & 2.46 & 9.71 & 2.27 & 10.07 & 0.28 & & \\
\hline \multirow[t]{2}{*}{ IE } & Urban & 2.55 & 1.51 & 3.85 & 1.97 & 3.77 & 0.25 & $10.04 * *$ & .1 \\
\hline & Indigenous & 1.80 & 1.49 & 2.49 & 1.62 & 2.58 & 0.27 & & \\
\hline \multirow[t]{2}{*}{ CS } & Urban & 3.62 & 2.07 & 4.23 & 2.03 & 3.98 & 0.19 & 0.43 & .01 \\
\hline & Indigenous & 2.80 & 1.79 & 3.49 & 1.74 & 3.79 & 0.21 & & \\
\hline \multirow[t]{2}{*}{ Total } & Urban & 33.08 & 6.37 & 45.66 & 9.23 & 43.53 & 0.90 & 3.17 & .03 \\
\hline & Indigenous & 28.18 & 6.90 & 38.58 & 8.46 & 41.09 & 0.98 & & \\
\hline
\end{tabular}

DP, making a plan; IO, making systematic observations; IT, employing equipment and tools; IM, measuring; IE, doing an experiment; CS, sharing

${ }^{* *} p<.01$ 
Table 8 ANCOVA results for comparisons of the 4- and 5-year-old groups

\begin{tabular}{|c|c|c|c|c|c|c|c|c|c|}
\hline \multirow[t]{2}{*}{ Practice } & \multirow[t]{2}{*}{ Age Group } & \multicolumn{2}{|c|}{ Pre-test } & \multicolumn{2}{|c|}{ Post-test } & \multicolumn{4}{|l|}{ ANCOVA } \\
\hline & & $M$ & $S D$ & $M$ & $S D$ & $M$ (adjusted) & $S E$ & $F$ & $\eta^{2}$ \\
\hline \multirow[t]{2}{*}{ DP } & 4 & 3.83 & 1.69 & 5.11 & 1.91 & 5.18 & 0.30 & 1.72 & .02 \\
\hline & 5 & 4.21 & 1.42 & 5.71 & 1.78 & 5.68 & 0.23 & & \\
\hline \multirow[t]{2}{*}{ IO } & 4 & 9.14 & 2.99 & 10.97 & 2.82 & 11.70 & 0.29 & 3.52 & .04 \\
\hline & 5 & 10.95 & 2.17 & 12.79 & 1.88 & 12.39 & 0.21 & & \\
\hline \multirow[t]{2}{*}{ IT } & 4 & 2.14 & 0.81 & 2.66 & 0.68 & 2.69 & 0.11 & 1.89 & .02 \\
\hline & 5 & 2.30 & 0.69 & 2.90 & 0.71 & 2.88 & 0.08 & & \\
\hline \multirow[t]{2}{*}{ IM } & 4 & 7.00 & 2.35 & 10.37 & 2.46 & 11.42 & 0.34 & $6.88^{* *}$ & .07 \\
\hline & 5 & 9.73 & 2.07 & 10.83 & 2.10 & 10.24 & 0.25 & & \\
\hline \multirow[t]{2}{*}{ IE } & 4 & 1.74 & 1.40 & 2.60 & 1.52 & 2.73 & 0.32 & 3.77 & .04 \\
\hline & 5 & 2.46 & 1.56 & 3.57 & 2.05 & 3.50 & 0.24 & & \\
\hline \multirow[t]{2}{*}{ CS } & 4 & 2.74 & 1.92 & 3.60 & 1.87 & 3.94 & 0.24 & 0.08 & .00 \\
\hline & 5 & 3.52 & 1.97 & 4.05 & 1.96 & 3.86 & 0.18 & & \\
\hline \multirow[t]{2}{*}{ Total } & 4 & 26.60 & 7.12 & 39.11 & 10.18 & 43.626 & 1.16 & 1.58 & .02 \\
\hline & 5 & 33.17 & 5.81 & 44.24 & 8.70 & 41.731 & 0.84 & & \\
\hline
\end{tabular}

DP, making a plan; IO, making systematic observations; IT, employing equipment and tools; IM, measuring; IE, doing an experiment; CS, sharing

${ }^{* *} p<.01$

\section{Discussion and Conclusion}

A quality and developmentally appropriate early STEM curriculum is critical for helping children develop scientific practices at a young age (e.g., Kähler et al., 2020; National Research Council, 2013). This study developed and implemented an effective module that helped preschoolers and kindergarteners of different cultural backgrounds and ages reinforce their scientific practices. This study found that after taking the module, all children performed better in overall scientific practices and every sub-practice. The children living in urban and Indigenous areas as well as the 4- and 5-year-old groups improved in overall scientific practices and every sub-practice.

While some early science curricula either did not evaluate children's science performances (e.g., Haus der kleinen Forscher Foundation, 2015) or evaluated children's performances mainly on their development of verbal scientific explanations (e.g., Peterson \& French, 2008), this study designed a performance assessment to more completely evaluate the effects on children's scientific practices. Such an evaluation, aligned with Unal and Saglam (2018) and Tekerci and Kandir (2017), supports the development of evidence-based curricula.

Some researchers have stated that young children could acquire inquiry abilities from free manipulation of materials, while others have argued for the importance of structured curricula that involve intentional teaching and scaffolding for children to learn science concepts and practices (French, 2004; Hsin \& Wu, 2011). In alignment with previous research on structured curricula, this study revealed the effectiveness of a project-based module on the improvement of children's scientific practices. In addition, among structured approaches, theme-based early science curricula have received 
more research attention (e.g., Tekerci \& Kandir, 2017; Unal \& Saglam, 2018), while research on project approach curricula for young children is scant. This study extends prior research on project-based learning by developing a project-based module for young children that provided abundant opportunities for them to ask questions, plan their investigations, conduct investigations, collaborate with peers, analyze data, use tools, and share results.

Few researchers have examined the effects of a science program on the scientific practices of children from different backgrounds. This study found that Indigenous children had lower initial achievement in scientific practices, which may be due to fewer socioeconomic resources in their families and limited science learning programs and institutes in their communities. However, by engaging in a quality science learning module in the public kindergarten, these children could improve as much as urban children. This finding implies that more quality early science curricula are needed to foster underrepresented children's scientific practices and to help them make a smooth transition to learning science at elementary school.

This study also adds to the literature by shedding light on young children's scientific practices. Regarding the practice of doing an experiment, the results of this study were consistent with those reported in previous research, finding that under adults' guidance, young children could learn how to do experiments and improve this practice over time (e.g., Dejonckheere et al., 2016; van der Graaf et al., 2016). In this study, the results from the post-tests showed that some of the 4- and 5-year-old groups were capable of identifying the controlling and manipulating variables and further explaining the effects of manipulating variables on the results. This study also extends previous studies by examining how children of different initial performances develop their practice of doing experiments. Although the ANCOVA results showed a similar level of development of the urban and Indigenous children, the urban children with better initial performances had a better score on the post-test than their counterparts after taking the module. Their better initial performances may stem from more resources and experiences in learning the control of variables strategy in cities. For example, during the pre-test, a city child shared his experiences of designing and conducting experiments in an afterschool science program. The results also imply that children with lower initial performances on doing experiments require more support and guidance from teachers to decrease the gap between them and advantaged students.

Regarding the practice of measuring, this study echoes Solomon's (2015) suggestion that early science intervention should instruct young children to use measuring tools with numbers. Furthermore, this study reveals that with adults' instruction, some children were able to use more tools for measurement, such as a stopwatch, thermometer, and scale. This study also deepened the understanding of the intervention effects on children of different ages. It showed that younger children (i.e., the 4-year-old group) could have better improvement when they were taught how to use the measuring tools. Also, the reason that the 5-year-old group did not progress more may have been because they had had many experiences of using tools before taking the module. However, to receive a higher score in the assessment, they needed to report their measurement with a number and a unit of measurement, such as centimeter or gram. Children learned the unit of time in the module but not other units of measurement. This finding provides insight into teaching more standard units of measurement in the future.

This research is subject to some limitations. The children's scientific practices were only evaluated by the assessment developed in this study, whereas how they performed scientific practices during class was not examined. More data sources about children's scientific 
practices would inform an in-depth understanding of children's development of scientific practices. Additionally, although teachers in this study had experience of incorporating children's cultural experiences into their curricula and were encouraged to integrate local culture and knowledge into this learning module, few teachers in Indigenous areas demonstrated cultural integration in the classroom. The module should have provided more activities for teachers to contextualize science in different ways, such as integrating Atayal culture and knowledge into the lessons. Future studies may explore how children would benefit from a culturally integrated science module. Also, how teachers use various strategies to foster children's scientific practices can be further examined.

Author Contribution The first and corresponding author, Ching-Ting Hsin: Conceptualization, Methodology, Validation, Formal Analysis, Investigation, Data Curation, Writing-Original Draft, Writing- Original Draft \& Revising, Project Administration, Funding Acquisition.

The second author, Hsin-Kai Wu: Conceptualization, Investigation, Resources, Writing- Review \& Editing, Project Administration, Funding Acquisition.

Funding This study was supported by the Ministry of Science and Technology in Taiwan under MOST 108-2628-H-007-001-MY3, MOST 107-2511-H-003-012-MY3, MOST 109-2511-H-003-015-MY3, and the "Institute for Research Excellence in Learning Sciences" of National Taiwan Normal University from The Featured Areas Research Centre Program within the framework of the Higher Education Sprout Project by the Ministry of Education in Taiwan.

Data Availability Data was organized and analyzed using qualitative and qualitative data analysis software NVivo and SPSS. We maintained an audit trail that recorded the entire analysis process and made it transparent (Huberman and Miles, 1994).

Code Availability Not applicable.

\section{Declarations}

Ethics Approval Not applicable. IRB review was not considered necessary by the funding institute.

Consent to Participate This study followed the ethical considerations in Taber (2014). Consent forms were collected from the parents of all participants, informing the research purposes and participation was voluntary and anonymous. Participants could withdraw from the research at any stage of the research and their performances in the study would not affect their learning. All parents of participants allowed us to use their data for research purposes.

Consent for Publication Not applicable.

Conflict of Interest The authors declare no competing interests.

Open Access This article is licensed under a Creative Commons Attribution 4.0 International License, which permits use, sharing, adaptation, distribution and reproduction in any medium or format, as long as you give appropriate credit to the original author(s) and the source, provide a link to the Creative Commons licence, and indicate if changes were made. The images or other third party material in this article are included in the article's Creative Commons licence, unless indicated otherwise in a credit line to the material. If material is not included in the article's Creative Commons licence and your intended use is not permitted by statutory regulation or exceeds the permitted use, you will need to obtain permission directly from the copyright holder. To view a copy of this licence, visit http://creativecommons.org/licenses/by/4.0/. 


\section{References}

Borgerding, L. A., \& Raven, S. (2018). Children's ideas about fossils and foundational concepts related to fossils. Science Education, 102(2), 414-439. https://doi.org/10.1002/sce.21331

Bullock, M., \& Ziegler, A. (1999). Scientific reasoning: Developmental and individual differences. In F. E. Weinert \& W. Schneider (Eds.), Individual development from 3 to 12: Findings from the Munich longitudinal study (pp. 38-54). Cambridge University Press.

Clements, D. H., \& Sarama, J. (2016). Math, science, and technology in the early grades. Future of Children, 26(2), 75-94. https://doi.org/10.1353/foc.2016.0013

Cohen, J. (1988). Statistical power analysis for the behavioral sciences (2nd ed.). Sage.

Cooper, G., Berry, A., \& Baglin, J. (2020). Demographic predictors of students' science participation over the age of 16: An Australian case study. Research in Science Education, 50, 361-373. https:// doi.org/10.1007/s11165-018-9692-0

Dejonckheere, P. J. N., De Wit, N. L., Van de Keere, K., \& Vervaet, S. (2016). Exploring the classroom: Teaching science in early childhood. European Journal of Educational Research, 5(3), 149-164. https://doi.org/10.12973/eu-jer.5.3.149

French, L. (2004). Science as the center of a coherent, integrated earlychildhood curriculum. Early Childhood Research Quarterly, 19, 138-149. https://doi.org/10.1016/j.ecresq.2004.01.004

Gelman, R., \& Brenneman, K. (2004). Science learning pathways for young children. Early Childhood Research Quarterly, 19(1), 150-158. https://doi.org/10.1016/j.ecresq.2004.01.009

Gelman, R., \& Brenneman, K. (2012). Moving young "scientists-in-waiting” onto science learning pathways: Focus on observation. In J. Shrager \& S. Carver (Eds.), The journey from child to scientist: Integrating cognitive development and the education sciences (pp. 155-169). American Psychological Association.

Greenfield, D. B. (2015). Assessment in early childhood science education. In K. C. Trundle \& M. Saçkes (Eds.), Research in early childhood science education (pp. 353-380). Springer. https://doi. org/10.1007/978-94-017-9505-0_16

Haus der kleinen Forscher Foundation. (2015). Pedagogic approach: A guide to facilitating learning in science, mathematics, and technology. Author.

Haus der kleinen Forscher Foundation. (2017). Inquiry-based learning in STEM: Science, technology, engineering and mathematics. Haus der kleinen Forscher Foundation.

Helm, J. H., \& Katz, L. G. (2016). Young investigators: The project approach in the early years (3rd ed.). Columbia University.

Hsin, C.-T., \& Wu, H.-K. (2011). Using scaffolding strategies to promote young children's scientific understandings of floating and sinking. Journal of Science Education and Technology, 20(5), 656666. https://doi.org/10.1007/s10956-011-9310-7

Huberman, A. M., \& Miles, M. B. (1994). Data management and analysis methods. In N. K. Denzin \& Y. S. Lincoln (Eds.), Handbook of qualitative research (pp. 428-444). Sage.

Jirout, J., \& Zimmerman, C. (2015). Development of science process skills in the early childhood years. In K. C. Trundle \& M. Saçkes (Eds.), Research in early childhood science education (pp. 143165). Springer.

Kähler, J., Hahn, I., \& Köller, O. (2020). The development of early scientific literacy gaps in kindergarten children. International Journal of Science Education, 42(12), 1988-2007. https://doi.org/10. 1080/09500693.2020.1808908

Kirkland, L. D., Manning, M., Osaki, K., \& Hicks, D. (2015). Increasing logico-mathematical thinking in low SES preschoolers. Journal of Research in Childhood Education, 29(3), 275-286. https://doi. org/10.1080/02568543.2015.1040901

Krajcik, J. S., \& Czerniak, C. M. (2018). Teaching science in elementary and middle school: A projectbased learning approach. Routledge.

Lin, T.-L., Kao, H.-L., Hung, S.-P., Chou, T.-L., \& Chen, Y.-C. (2017). 台灣原住民科學教育的回顧與 展望 [A review and outlook on science education of Indigenous students in Taiwan]. Taiwan Indigenous Studies Review, 22, 77-104.

MacDonald, A., Huser, C., Sikder, S., \& Danaia, L. (2020). Effective early childhood STEM education: Findings from the little scientists evaluation. Early Childhood Education Journal, 48(3), 353-363. https://doi.org/10.1007/s10643-019-01004-9

Mantzicopoulos, P., Patrick, H., \& Samarapungavan, A. (2013). Science literacy in school an home contexts: Kindergarteners' science achievement and motivation. Cognition and Instruction, 31(1), 62-119. https://doi.org/10.1080/07370008.2012.742087 
Mead, N., Grigg, W., Moran, R., \& Kuang, M. (2010). National Indian education study part II: The educational experiences of American Indian and Alaska Native students in grades 4 and 8 . National Center for Education Statistics, US Department of Education.

Ministry of Education. (2017). 幼兒園教保活動課程大綱 [Early childhood education and care curriculum framework]. K-12 Education Administration, Ministry of Education in Taiwan.

Monteira, S. F., \& Jiménez-Aleixandre, M. P. (2016). The practice of using evidence in kindergarten: The role of purposeful observation. Journal of Research in Science Teaching, 53(8), 1232-1258. https://doi.org/10.1002/tea.21259

National Research Council. (2012). A framework for K-12 science education: Practices, crosscutting concepts, and core ideas. National Academies Press.

National Research Council. (2013). Next generation science standards: For states, by states. National Academies Press.

Peterson, S. M., \& French, L. (2008). Supporting young children's explanations through inquiry science in preschool. Early Childhood Research Quarterly, 23, 395-408. https://doi.org/10.1016/j.ecresq.2008. 01.003

Piekny, J., \& Maehler, C. (2013). Scientific reasoning in early and middle childhood: The development of domain-general evidence evaluation, experimentation, and hypothesis generation skills. British Journal of Developmental Psychology, 31(2), 153-179. https://doi.org/10.1111/j.2044-835X.2012.02082.x

Richardson, J. T. E. (2011). Eta squared and partial eta squared as measures of effect size in educational research. Educational Research Review, 6(2), 135-147. https://doi.org/10.1016/j.edurev.2010.12.001

Samarapungavan, A., Mantzicopoulos, P., Patrick, H., \& French, B. (2009). The development and validation of the science learning assessment (SLA): A measure of kindergarten science learning. Jourmal of Advanced Academics, 20(3), 502-535. https://doi.org/10.1177/1932202X0902000306

Siraj, I., \& Mayo, A. (2014). Social class and eudcational inequality: The impact of parents and schools. Cambridge University Press.

Solomon, T. L., Vasilyeva, M., Huttenlocher, J., \& Levine, S. C. (2015). Minding the gap: Children's difficulty conceptualizing spatial intervals as linear measurement units. Developmental Psychology, 51(11), 1564-1573. https://doi.org/10.1037/a0039707

Taber, K. S. (2014). Ethical considerations of chemistry education research involving 'human subjects'. Chemistry Education Research and Practice, 15(2), 109-113. https://doi.org/10.1039/c4rp90003k

Tekerci, H., \& Kandir, A. (2017). Effects of the sense-based science education program on scientific process skills of children aged 60-66 months. Eurasian Journal of Educational Research, 68, 239-256. https:// doi.org/10.14689/ejer.2017.68.13

Unal, M., \& Saglam, M. (2018). Examination of the effect of the GEMS program on problem solving and science process skills of 6 years old children. European Journal of Educational Research, 7(3), 567581. https://doi.org/10.12973/eu-jer.7.3.567

van der Graaf, J., Segers, E., \& Verhoeven, L. (2015). Scientific reasoning abilities in kindergarten: Dynamic assessment of the control of variables strategy. Instructional Science, 43(3), 381-400. https:// doi.org/10.1007/s11251-015-9344-y

van der Graaf, J., Segers, E., \& Verhoeven, L. (2016). Discovering the laws of physics with a serious game in kindergarten. Computers and Education, 101, 168-178. https://doi.org/10.1016/j.compedu.2016.06. 006

Woods-McConney, A., Oliver, M. C., McConney, A., Maor, D., \& Schibeci, R. (2013). Science engagement and literacy: A retrospective analysis for Indigenous and non-Indigenous students in Aotearoa New Zealand and Australia. Research in Science Education, 43, 233-252. https://doi.org/10.1007/ s11165-011-9265-y

Publisher's Note Springer Nature remains neutral with regard to jurisdictional claims in published maps and institutional affiliations. 